\section{An Inexpensive System for Controlling Carbon Dioxide Concentration while Working in Enclosed Environments}

\author{
James D. Stewart and Pierre Y. Bernier' \\ Natural Resources Canada, Canadian Forest Service-Quebec Region, P. O. \\ Box 3800, Sainte-Fey, Que. G1V 4C7, Canada
}

Additional index words. growth chamber, plant physiology, gas exchange

In pursuing our research on the responses of black spruce[Picea mariana (Mill.) B. S. P.] seedling gas exchange and water relations to diverse environmental conditions, we explored various options for $\mathrm{CO}_{2}$ control in our walk-in growth chambers. Early measurements had shown that our chambers (model GRW-36; Environmental Growth Chambers, Winnipeg, Manitoba) had an air exchange rate of $\approx 3.5$ times per hour, and that the presence of one investigator would cause $\mathrm{CO}_{2}$ concentration to rise by $300 \mathrm{ppm}$ above ambient within 20 min of entry into the chamber (Fig. 1). This was a dramatic change for our plant subjects, and a potential source of error in our experiment, because $\mathrm{CO}_{2}$ concentration increases of such a magnitude have large demonstrated effects on rates of various physiological responses (Amthor, 1991; Monson, 1985; Mott, 1990; Tyree and Alexander, 1993). After a survey of possible solutions to this problem, we devised a method of $\mathrm{CO}_{2}$ exhalation control that is effective and inexpensive.

Moderately priced respirator masks made of molded plastic were purchased from an industrial safety supplies store. The removable inlet and outlet valves were reversed to ensure free inhalation and controlled exhalation through the cartridge outlet. Because the respirator manufacturers each have their own proprietary threads on connectors, standard plumbing fixtures could not be attached directly to the masks. We, therefore, used a cartridge designed for the masks to make the

Receivedforpublication12July 1993. Accepted for publication 14 Dec. 1993. Support for this research wasprovidedbythe Canadian Forest Service-Quebec Region, Research Project CFL-44. A Natural Sciences and Engineering Research Council of CanadaForestry Postdoctoral Fellowship awarded to J.D.S. is gratefully acknowledged. The cost of publishing this paper was defrayed in part by the paymentofpage charges. Under postal regulations, this paper therefore must be hereby marked advertisement solelyto indicate this fact.

'To whom reprint requests should be addressed. without great discomfort. With two masks attached to the same vacuum line, the suction was just able to keep up with the rate of exhalation. Carbon dioxide contamination was avoided, but the masks were not as comfortable.

Although, to our knowledge, never reported in the technical literature, using a vacuum to remove breath-derived $\mathrm{CO}_{2}$ from growth chambers is not new. However, a vacuum itself is not enough, as the $\mathrm{CO}_{2}$ must be discharged at some distance from the chamber. Discharging the $\mathrm{CO}_{2}$ into the room containing the growth chamber will elevate ambient $\mathrm{CO}_{2}$ and cause some of it to leak back into the chamber. For facilities that lack a vacuum system, an air pump, such as a vacuum cleaner, outside the chamber that exhausts the air far from the chamber is a possible alternative. Finally, using a plastic bag as an expandable buffer decreases the suction requirement of the vacuum system, thereby permitting a greater effectiveness to be achieved even with modest air flow rates.

\section{Literature Cited} expandable buffer volume for the system.

In practice, this system proved to be highly effective. When reasonable care was taken, all the $\mathrm{CO}_{2}$ from exhalations was removed from the chamber and exhausted from the building via the central vacuum system. With a flow of $\approx 50$ liters $\cdot \mathrm{min}^{-1}$, the suction was sufficient to create constant air movement through the mask, which kept it cool and dry. The mask did not need to be attached tightly to the face to prevent leaks and therefore could be worn

Amthor, J.S. 1991. Respiration in a future, higher $\mathrm{CO}_{2}$ world. Plant Cell Environ. 14:13-20.

Morison, J.LL. 1985. Sensitivity of stomata and water use efficiency to high $\mathrm{CO}_{2}$. Plant Cell Environ. 8:467-474.

Mott, K.A. 1990. Sensing of atmospheric $\mathrm{CO}_{2}$ by plants. Plant Cell Environ. 13:731-737.

Tyree, M.T. and J.D. Alexander. 1993. Plant water relations and the effects of elevated $\mathrm{CO}_{2}$ : $\mathrm{A}$ review and suggestions for future research. Vegetatio 104:47-62.

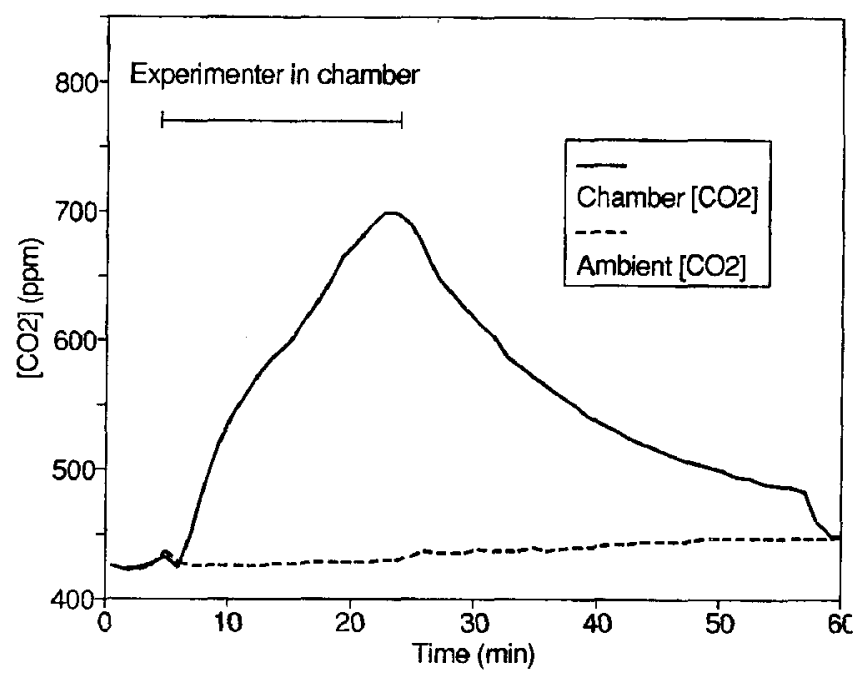

Fig.1.Carbondioxide concentration in a $12-\mathrm{m}^{3}$, walk-in growth chamber with one experimenter inside the chamber for $20 \mathrm{~min}$ without any control of exhaled $\mathrm{CO}_{2}$. Air exchange rate of the chamber is 3.5 times perhour.TheriseinambientCO $\mathrm{C}_{2}$ (dashed line) reflects workday $\mathrm{CO}_{2}$ accumulation inside the building. 